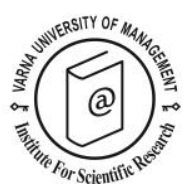

\title{
Tourist destinations displayed on film and television. Influence on their reputation, brand image and consumer choice
}

\author{
Sara Alexandra Soares da Mata Nunes ${ }^{1}$
}

Received: 12/03/2018

${ }^{1}$ Assistant Professor at Stenden University of Applied Science, Qatar. P.O.Box 36037, Doha, Qatar. Phone: +974 44888116/26; Direct number: +974 448776740/52 - Ext. 400. E-mail: sara.nunes.pt@gmail.com

Supervisors: Alejandro del Moral Agundez Julia Fragoso da Fonseca

Institution awarding the Ph. D. Degree: University of Extremadura, Faculty of Economics and Business Sciences, Spain

Date of defence: 03/04/2017

(C) 2018 Varna University of Management. All rights reserved

Citation: Nunes, S. (2018) Tourist destinations displayed on film and television. Influence on their reputation, brand image and consumer choice. Doctoral Dissertation Summary. European Journal of Tourism Research 20, pp. 129-133

\section{Goal and objectives of the dissertation Goal}

The main goal of this research is to reflect the importance of the displayed images, in cinema productions, on the motivations that lead into picking a certain tourism destination by the consumer, and at the same time to consider whether they contribute to build the brand value of a specific destination when it comes to active awareness and brand image.

For that reason, we stress the importance that the images, exhibited in cinematographic productions, have on the construction of the brand value of a tourism destination.

\section{Objectives}

Objective 1 - To measure the attitude of consumers towards film tourism. In particular, to determine the possible influence that the images of a tourism destination displayed in cinematographic or TV productions have:

$\checkmark$ On the brand value of a destination regarding the brand image $(\mathrm{O} 1 \mathrm{a})$.

$\checkmark$ On consumer intention to travel to the tourism destination (O1b).

Objective 2 - To measure the importance of film tourism as a motivational factor (push and pull) regarding tourism destination's decision.

Objective 3 - To measure the importance of the information sources linked to film tourism (portals and promotional activities undertaken to promote film and TV productions) and the impact the latter have on consumers' intention and desires to choose and visit destinations.

Objective 4 - To analyse if the attitudes and behaviours of consumers about film tourism change according to the following factors: 
Tourist destinations displayed on film and television. Influence on their reputation, brand image and consumer choice. Doctoral Dissertation Summary.

$\checkmark$ They have already taken a trip in this scope (O4a).

$\checkmark$ They have future intention to carry out trips in this scope (O4b).

$\checkmark$ Gender (O4c).

$\checkmark$ Age (O4d).

$\checkmark$ Educational level (O4e).

\section{Methodology}

This research is based on qualitative and quantitative approaches. The qualitative part comprises bibliographical reviews on tourists' motivations, tourism destinations, brands, and cinematographic tourism; as well as interviews. Besides, the quantitative phase consists on data collection, analysis, experimentation, and reformulation of the hypothesis.

Our research model (refer to figure 1) is based on the idea that films or TV productions are powerful mechanisms to promote everything that is exhibited in them. In this case, places can be promoted as important tourism destinations if it is properly managed. Thus, the images displayed in a film or in a TV production has the power to enhance the brand image, brand awareness of a destination, as well as tourist's motivations and visit intention. In addition, even the promotional mix used to advertise the actual films and TV productions represent, itself, a strong tool to increase the visit intention to the tourism destination.

To measure the hypothesis and to achieve the study, we have chosen to do a questionnaire survey based on the findings of the qualitative approach and exploratory interviews. A pre-test was also prepared in order to analyse the feasibility of the questionnaire.

The sample is composed of Portuguese respondents aged over 30 years (and thus pay for their own travels), who are leisure tourists, and are interested in film productions. For our investigation, we used a non-probabilistic sample. Regarding the sociodemographic characterization of the sample, which was composed of 310 individuals, the majority are between 30 and 40 years of age $(68.9 \%$ of our sample), are mostly female respondents $(57 \%$ of our sample), have a qualification at the level of a bachelor's degree (46.9\% of our sample) and reside in the greater Lisbon area $(37.4 \%$ of our sample).

To obtain an accurate result, various statistical methods were used (frequency distributions and descriptive statistics,

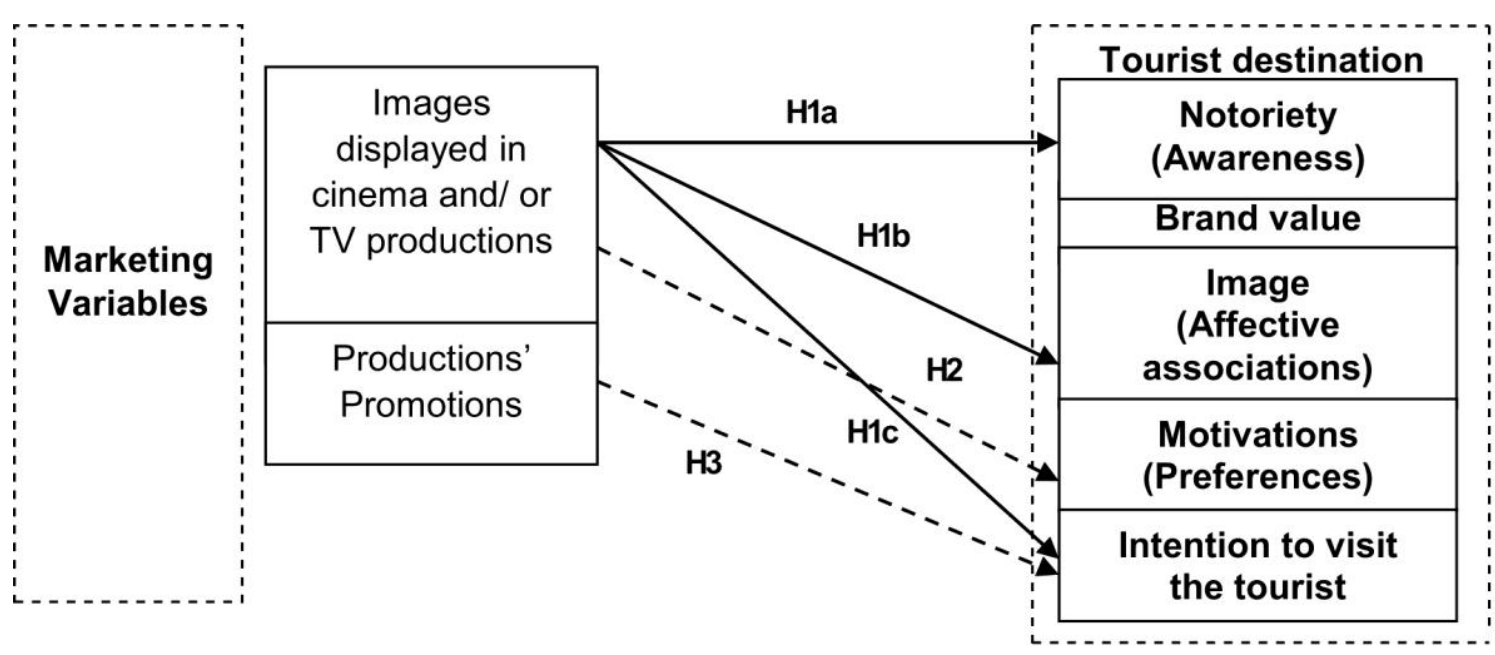

Figure 1. Research Model 
confidence interval calculations, t-test student, ANOVA, factorial and segmentation analysis).

\section{Results}

In our study, we found that the most visited destinations regarding film tourism are UK, Portugal, Spain, Italy and Morocco $(36 \%$ of our sample already visited a destination related to film tourism). The fact that these destinations are geographically located in some proximity to Portugal may have influenced the result. However, the destinations that the respondents selected as preferred ones to visit on this field $(63 \%$ of our sample) are USA, UK, New Zealand and Thailand, which are, in substance, the main world destinations in the field of film tourism.

Regarding the attitude of the consumers towards film tourism respecting awareness, destination image and intention to visit, there is strong agreement concerning the following aspects: "film tourism leads to the intention and desire to visit the destination" (4.38/ $87.3 \%$ of our sample), "favours its brand image" (4.19/ $85.9 \%$ of our sample), and it "increases its notoriety" (4.18/ $83.6 \%$ of our sample).

However, when we analysed the importance of film tourism regarding tourists' motivations (pull and push factors), the scenario is opposite. According to consumers, the elements related to film tourism are the attributes that respondents least value regarding pull motivations (average value of 9.6/100) and image of a tourism destination (pull). Similarly, 'the importance of film tourism' in the motivation to travel to a tourism destination (push), is the second attribute less valued by respondents (average value of 9.2/100).

On the topic of the attitude of the consumers towards the advertising of tourism destinations, which is received indirectly through cinematographic and TV productions, all are considered important by the consumers (more than 3 , the intermediate point of measurement scale); although specific ones related to film tourism generally occupy the lowest positions.

In addition to our previous analysis, we also decided to elaborate a segmentation study and we can conclude that the attitude toward film tourism and its importance as a motivating factor and source of information for the destination choice, is clearly more favourable or greater among those who have already made trips in the field of film tourism and among those who intend to do so in the future. We could not find any differences regarding gender; nevertheless, we found some differences concerning age and educational level. In fact, when age and educational level increase, more importance is given to the brand value of a destination (the brand image and awareness through film productions).

Last but not least, the cluster analysis has allowed us to identify four groups of tourists divided according to their position regarding film tourism. The groups called "involved" and "attracted" (constituting $63.6 \%$ of our sample) are the most involved, due to a greater push motivation, a more favourable attitude towards film tourism and are the ones who give greater importance to the sources of information related to the latter. In these groups, there are the majority of consumers who stated to have visited a destination related to film tourism, those who have a greater interest in doing so in the future, and the respondents with higher age level.

Through all the results presented in the study, it can be concluded that film tourism causes a significant influence on the audiences of a film or a TV production; stimulates the intention/ desire to visit the destination exhibited; and gives a higher value to the image and the awareness of the latter.

\section{Theoretical conclusions}

From the literature review carried out, it can be concluded that when a tourism destination is competitive, it can become a powerful brand, but in the case the latter does not have a brand the consumer is not aware of its 
Tourist destinations displayed on film and television. Influence on their reputation, brand image and consumer choice. Doctoral Dissertation Summary.

identity. This absence thereof can lead to a significant loss of potential visitors.

One of the ways to achieve this brand notoriety is to bet on film tourism. The latter is due to the fact that it is a lucrative and growing sector providing economic benefits and reinforcing brand equity elements such awareness and brand image. The best example in this field is New Zealand; actually we cannot talk about film tourism without mentioning this destination. In fact, they used the film productions to increase the image of the country and thereby tourists' attraction, turning up from a non-relevant tourism destination to one of the main ones in the world.

\section{Practical application of the dissertation}

This research complements previously carried out studies, in which it was proved that film tourism generates an emotional involvement, plays an important role regarding destination's promotion, brings advantages and benefits, and last, influences positively destination's image. Therefore, we would like to encourage a broader study of this topic so that it can be used as a tool in which to increase tourism ratings.

Furthermore, this research is a pioneering study respecting the correlation between brand equity regarding tourism destination and film tourism. As a consequence, the expected result of this study aims to allow destinations' managers to work closely with film tourism to reveal its importance to the world, notedly Portugal, with $63 \%$ of our sample stating a need or a desire to visit a film tourism destination.

\section{Content of the dissertation}

Abstract of Chapter 1: Tourist's Motivation and Behaviour

The chapter focuses on the study of consumer's behaviour as one of the most researched areas in the tourism field due to its pre-eminence for tourism destinations to pinpoint tourist's expectations, perceptions and motivations. The latter would allow anticipating needs and developing appropriate marketing strategies to attract tourists, keeping and increasing their competitiveness.

\begin{abstract}
Chapter 2: Tourism Destinations and Competitiveness

The chapter investigates tourism destinations and their competitiveness. Actually this field of study has grown in recent years as a result of some changes; it was common to state that just places graced by nature or history could become important tourism destinations; however, nowadays this idea is completely outdated. Tourists are attracted to a destination as a result of their potential selfexperiences. For that reason, competitiveness of tourism destinations should, currently, be focused through a multidimensional and complex perspective.
\end{abstract}

\section{Abstract of Chapter 3: Tourism Destinations as Brands}

The chapter elaborates an overview on the topic of tourism destinations' brands. In recent years the concept of a brand was needful since everyone recognises the importance regarding consumer's choices, that's why all organisations, political parties, and even tourism destinations are motivated to build and be represented by a brand, to increase the probability of being chosen by consumers.

\section{Abstract of Chapter 4: Film Tourism Concepts and Impacts}

This chapter pinpoints the correlation between cinema and tourism; usually, it is difficult to see thereof between both phenomena, we simply have the idea that they are two extremely powerful forces. Nevertheless, when these forces are interconnected, they represent an unavoidable bout of success in the perspective of tourism images, awareness, and intention to visit a destination displayed in cinematographic or TV productions. The relation between these two fields is no longer casual; these two sectors are working together when production is being planned. In this context, film tourism is an effective marketing tool. For that reason tourism destinations should use the latter as a promotion strategy. 


\begin{abstract}
Chapter 5: Methodology
In order to achieve our objectives in this chapter, with respect to the methodology, we discuss the approach undertaken in this investigation regarding empirical research and precisely the quantitative method. We chose this methodology due to the fact that it allowed us to generalise the results through survey, experimentation, questions, hypotheses reformulation, and collection of data. For carrying out our goals on this study we applied the research model from Quivy and Campenhoudt (2003).
\end{abstract}

\section{Abstract of Chapter 6: Results}

In this chapter we present the main results regarding data analysis, divided into four parts. The main ones are the sample profile analysis, which encompasses the results concerning attitude of consumers towards film tourism on the topic of brand image, brand awareness, intention to travel, and motivation. The second part is hypotheses contrast and discussion, and the last but not least is the segmentation analysis.

\section{Abstract of Chapter 7: Conclusion \\ A summary of the relevant points of this work is presented in this chapter; the main parts are the thesis contributions, limitations, and suggestions respecting future ways of research.}

\section{References:}

Quivy, R. \& Campenhoudt, L. V. (2003). Manual de Investigação em Ciências Sociais. Gradiva.

Woodside, A. G. \& Lysonski, S. (1989). A general model of traveler destination choice. Journal of Travel Research, 27(4), 8-14. 